\title{
The use of soft wall containers for transporting vegetables
}

\author{
N N Mirzaev ${ }^{1}$, G Sh Zhuraeva Z $^{1}$ R Hamroev $^{1}$ \\ ${ }^{1}$ Tashkent State Technical University named after Islam Karimov Islam, University street №2, Tashkent city; Uzbekistan \\ E-mail: gulchehra2767@mail.ru
}

\begin{abstract}
Annotation. The paper considers the use of soft containers (MCs) for transporting vegetables, particularly root crops. Until recently, MCs, simply put bags, were used in agriculture to transport goods weighing up to $100 \mathrm{~kg}$. As the proportion of mechanisation is increasing, the use of MCs in larger sizes is becoming more and more important. This article examines the wall pressure of small and large-sized MCs and compares it to the strength of polypropylene fabric. As a result of calculation of pressure on walls of MK it is shown possibility of use of polypropylene PP cloth of various density.
\end{abstract}

\section{Introduction}

Big-bags (soft containers, big-bags, IBCs, big-bags) are widely used universal packaging, which is expanding every year in various sectors and industries (agriculture, chemical industry, food industry, construction, etc.). Large size big-bags are designed for transportation and storage of bulk, ground, fractionated, small-piece materials. Big bags can work with the customer's specific wishes and dreams. Can be used as disposable or reusable packaging.

Soft containers, or big bags, occupy a special place among today's conventional shipping containers.

They are widely used in dissipating loads. These are dispersed, powdered products (flour, cement, beryllium concentrate), soured (sugar, salt, grits), granular (mineral fertiliser, polyethylene, polystyrene), small, medium and large spring-spring materials (construction materials, ferroalloys, concentrates. ). Soft containers can be used not only for transport but also for long-term storage of the product. In this case, the environment is protected from contamination, product quality is preserved and the incidence of disease is close to zero.

\section{Materials and research methods}

The widespread use of soft containers in the world today has several advantages over other types of containers (metal, wooden, plastic, small wooden crates, iron barrels, etc.):

- small transport capacity factor $(0.01 \ldots .0 .02)$;

- low price (5-10 USD per tonne of cargo);

- impossibility of complex mechanisation of loading, unloading, storage when using conventional bags.

Achieve a high utilisation rate of storage space when using flexible containers, especially when loading upwards. Transport and storage of flexible containers has increased dramatically in recent years $[1,2]$.
Experimental industrial soft containers have been produced for the transport of liquid foodstuffs such as pistachio oil. The flexible containers, hermetically sealed with a dense material, are then placed on a platform (1000 $\mathrm{x} 1200 \mathrm{~mm}$ ) and fitted with fasteners that are positioned at the corners.

The soft container is filled using a special valve with a pump. Platforms can be loaded in closed wagons, largecapacity containers. The widespread and effective use of soft containers is now a serious competitor to traditional containers.
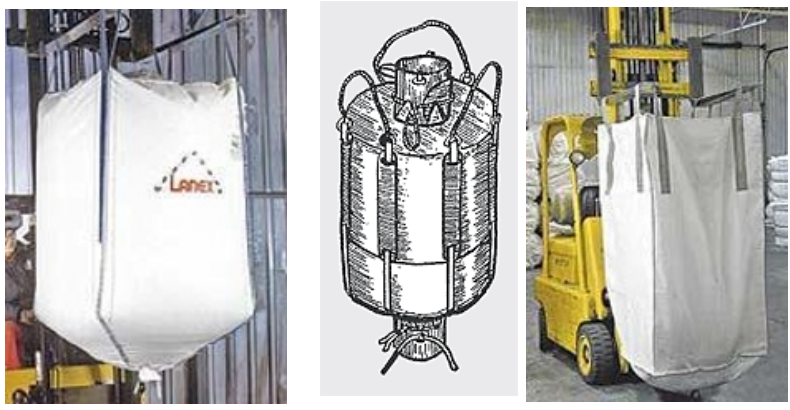

Fig.1. The first modern soft containers.On the left is the Taikon soft container. In the middle is a $95 \times 95 \times 130$ four-lane single-layer bottom unloading unit.

Soft containers were first manufactured in 1919 by the Japanese Taiyo Kogro Co. The farm was designed to carry a small load on top of a soft container, called a Taikon', and to transport scattered cargo by rail. The cargo then began to be used in the US and Western European countries.

For the first examples, natural fibres-cotton tents, tarpaulins and so on-were used. They were not very strong, rotted quickly and did not have a long lifespan, so the external support system, where supports are installed inside or outside, consists of uprights with a rectangular frame. 
In the mid-twentieth century, the development of the chemical industry in the $1950 \mathrm{~s}$ and $1970 \mathrm{~s}$ saw the use of synthetic polyamide and plywood fibres for the edges of shipping containers. Polyamide fibres (nylon, kapron, perlon, etc) are very strong and resistant to chemicals, water and forces. Its disadvantage is that it wears out when exposed to light and its elongation factor is relatively high.

Polyester fabrics (teripen, tetran, diopen) are strong, resistant to sunlight and weathering, but tend to collect static electricity.

Fabrics made from synthetic fibres (viscose, rayon, artificial silk) are also used in cargo containers, as they lose their initial $60 \%$ strength due to moisture and subsequent hydrolysis in their strength and durability.

Freight containers (big bags) are manufactured in hooktype, ring-type, before and after load elements. Cargo containers with the following characteristics are used in CIS countries:

- SPK-1,5 m is mainly designed for loader of two-layer perforated container with 4 holes for polystyrene transport, intended for loading and unloading;

- KC-Superphosphate, designed for granulated polyethylene, rubberised fabric tray with the same dimensions as the belt material, volume $1.3 \mathrm{~m} \mathrm{3}$. length $910 \mathrm{~mm}$, width $700 \mathrm{~mm}$, height $180 \mathrm{~mm}$, load capacity 1.5 $\mathrm{t}$.

For various loads, visnox, kapron, kowtow (grades Skms, nk, ski and SKD) of rubber compounds, lifting holes - belt in $\mathrm{MkR}$, iron ring in $\mathrm{J}$.

Due to the addition of rubber as a fabric in the above types, the weight rose to $95 \mathrm{~kg}$ and sometimes did not fold.

To date, more than 2.000 patents have been granted for flexible containers. Although the number of patents is high, their basic elements remain the same; Loading and unloading units, cargo elements, eyelets for suspension, document pockets. Soft packagings are made of different fabrics depending on the weight of the cargo and the intended use of the top layer material; some layers are cylindrical in shape, sometimes parallelepipedic, once filled, the load is made of 1-2 layers.

Big bags (soft containers, big-bags) are a widely used all-purpose container. The most commonly used sizes of soft containers are:

- two lane, one layer, two lane, two layer;

- 75x75x125 double strip, single layer;

- 75x75x125 two strips, two layers;

- 75x75x150 double strip, single ply;

- 95x95x130 four-layer, single-ply;

- 95x95x150 four-lane, single-ply;

- 95x95x180 four-lane, single-layer.

Consideration should be given to launching the production of internationally widely used big bags in Uzbekistan, researching, calculating the pressure in the bags, finding fabrics to withstand this pressure, and sewing the soft containers.

To determine the amount of product pressure on the wall of a soft container, consider the design of the container (Figure 2).

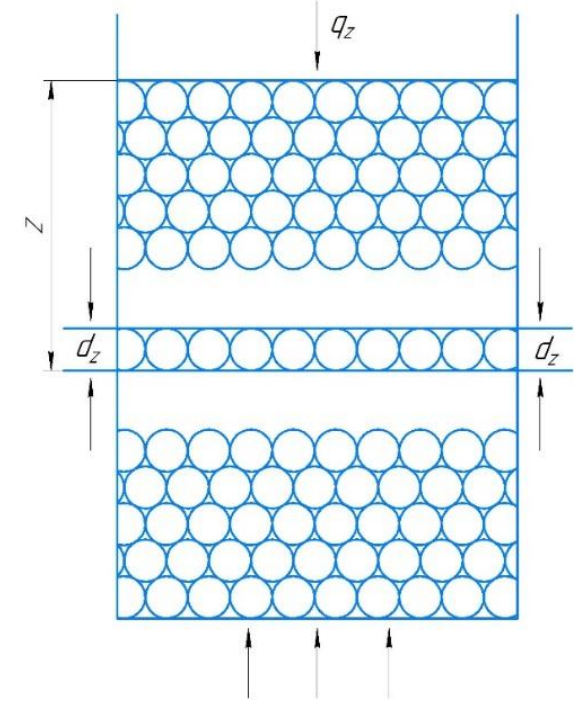

Fig.2. Schematic for calculating the magnitude of forces acting on the walls of soft containers in the layer $\mathrm{q}_{\mathrm{x}}$ at depth $\mathrm{Z}$

From the upper surface we separate an elementary layer $\mathrm{dz}$ at depth $\mathrm{Z}$, and if a force $\mathrm{q}_{\mathrm{z}}$ acts on the mass of product in the layer from above, the force $\mathrm{q}_{\mathrm{z}}+\mathrm{dq}_{\mathrm{z}}$ from below and friction forces with the wall. The force acting on the load from above is negative.

The equation of forces is expressed as follows:

$$
\gamma_{z} \mathrm{Sd}_{\mathrm{z}}+\mathrm{Sq}_{\mathrm{z}}-\mathrm{Sq}_{\mathrm{z}}-\mathrm{Sd}_{\mathrm{z}}-\mathrm{fEq}_{\mathrm{z}} \mathrm{S}=0
$$

Taking into account the boundary conditions, ie integrating the differential equation $\mathrm{q}_{\mathrm{z}}=0$ at $\mathrm{Z}=0$, we obtain the following expression [3]:

$$
\mathrm{q}_{\mathrm{z}}=\frac{\gamma S}{U E f}\left(1-\mathrm{e} \frac{U E f z}{s}\right)(\mathrm{Pa})
$$

here $\mathrm{q}_{\mathrm{z}}$ - vertical pressure, $\mathrm{N} / \mathrm{m}^{2} ; \mathrm{z}$ - comparative weight, $\mathrm{N} / \mathrm{m}^{3} ; \mathrm{S}$ - horizontal cross-sectional area of the container, $\mathrm{m}^{2}$; $\mathrm{U}$ - perimeter of the container, $\mathrm{m}$; E - coefficient of lateral friction; $\mathrm{f}$ - friction coefficient.

Thus, if we consider a horizontal layer of product (potatoes, apples, pears, carrots, etc.) which has to be brought to equilibrium, and calculate the impact forces, we will be able to find the pressure $\mathrm{qZ}$ at depth $\mathrm{Z}$.

For example, the pressure qz acting on the container wall and the pressure $\mathrm{qx}$ on the product are calculated in relation to the potato and carrot products.

\section{Research results and discussion.}

Soft containers of $500-1000 \mathrm{~kg}$ are used on an industrial scale. Potatoes have a density of $650 \mathrm{~kg} / \mathrm{m}^{3}$ and carrots a density of $550 \mathrm{~kg} / \mathrm{m}^{3}$. Here is the methodology for calculating a simple bag. At the depth of the container with radius $\mathrm{R}=0.25 \mathrm{~m} \mathrm{Z}$ the friction angle of the product is 250. 
Table 1. Table for calculating the pressure of the potatoes on the tank bottom and wall

\begin{tabular}{|c|c|c|c|c|c|c|c|c|c|c|}
\hline Feature & \multicolumn{10}{|c|}{ Depth of measurement site, $\mathrm{m}$} \\
\hline $\mathrm{Z} \mathrm{m}$ & 0.1 & 0.2 & 0.3 & 0.4 & 0.5 & 0.6 & 0.7 & 0.8 & 0.9 & 1.0 \\
\hline $\mathrm{q}_{\mathrm{z} \text {, Па }}$ & 4600 & 8490 & 12020 & 15560 & 18740 & 20160 & 22280 & 24050 & 25460 & 26880 \\
\hline $\mathrm{q}_{\mathrm{x}, \text { Па }}$ & 1840 & 3390 & 4810 & 6220 & 7500 & 8060 & 8890 & 9620 & 10180 & 10750 \\
\hline
\end{tabular}

Assuming $\mathrm{S}=\pi R^{2}, \mathrm{~S}=0.196 \mathrm{~m}^{2}$, with $\mathrm{U}=2 \pi R, \mathrm{U}=$ $1.57 \mathrm{~m}$

The coefficient of internal friction of the product is equal to the tangent of internal friction:

$$
\mathrm{f}=\operatorname{tg} \alpha=\operatorname{tg} 25^{0}=0.4663
$$

The coefficient of lateral pressure $E=\frac{1-\sin \alpha}{1+\sin \alpha}$, sin $\alpha=\sin 25^{\circ}=0,4226$ if $\mathrm{E}=0.4$ and find $\mathrm{q}_{\mathrm{z}}$ and $\mathrm{q}_{\mathrm{x}}$ from formulae (2) and (3).

Assume that the container size is $95 \times 95 \times 1300 \mathrm{~cm}$ and in the following table we calculate the impact of the potatoes on the wall.

Table 2. Calculate the potato effect on the wall

\begin{tabular}{|l|c|c|c|c|}
\hline Feature & $\begin{array}{c}\text { Z.m } \\
\text { depth }\end{array}$ & $\begin{array}{c}\text { container } \\
\text { width a, } \mathrm{M}\end{array}$ & $\begin{array}{c}\text { container } \\
\text { length } \mathrm{b}, \mathrm{M}\end{array}$ & $\mathrm{q}_{\mathrm{x} \text { МПа }}$ \\
\hline Indicators & 1.3 & 0.95 & 0.95 & 0.85 \\
\hline
\end{tabular}

The relationship between the pressure on the walls and bottom of small and large volume flexible containers and the weight of the product inside the container is shown in the following graph (Fig. 3).

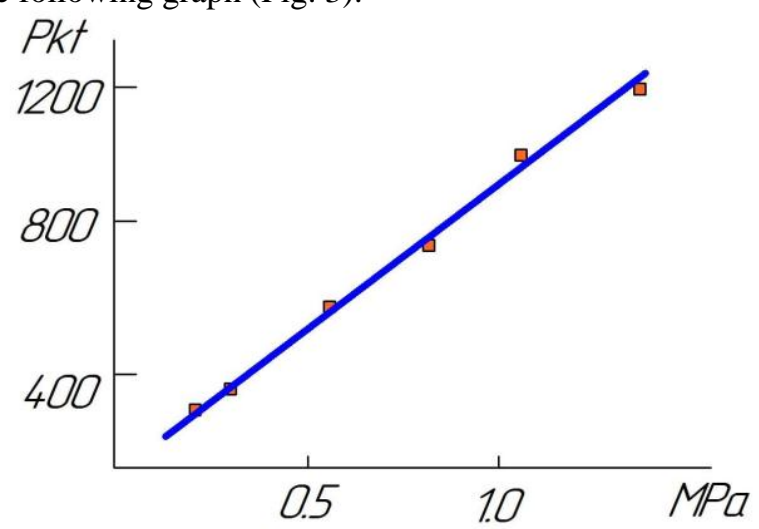

Fig.3. Pressure on the walls of the soft container.

As can be seen from the graph, the wall pressure in the large container did not exceed 1.5 MPa.

In recent years, soft containers have been manufactured from polypropylene. PP can withstand pressures up to 40 $\mathrm{MPa}$.

Such high-strength polypropylene fabrics are used to produce very large containers of 3-4 tons [4].

This means that small soft containers for agricultural products can be made from thin polypropylene fabric and large bags from thicker fabric, and orders can be made according to the specifications of polypropylene fabric.

\section{Conclusion}

As mentioned above, big bags can also be used to transport agricultural products. As a result of using soft containers to transport finished fruit from agricultural products, the cost of transporting, loading and storing the product will be drastically reduced.

The price of the product will be cheaper. Soft containers can be reused. By placing the product in soft containers in the field and sending it to the right shop or storage facility, the use of mechanised loading and unloading increases productivity by a factor of 5, and the cost of containers is drastically reduced.

Nowadays, bags of $30-80 \mathrm{~kg}$ used for loading, unloading and storage in the fields can be called small big bags, because the maximum load, mechanical properties and other material parameters of a bag can be determined from the physicalmechanical properties.

\section{References}

1. Melekhova L V,Tektutyeva L A. Pressure distribution in soft containers for storage of fruit and vegetable products. // Storage and Processing of Agricultural Raw Materials, No.10. 2012. 54-55.

2. Khalipov, Sergey Vasilievich. Customs peculiarities of containers' import in the Eurasian Economic Union / S V, Khalipov: direct // Russian Foreign Economic Bulletin. - 2020. - № 4. - 48-57

3. Umarov V F, Salimov G I. TashGTU Use of optimal containers for transportation and storage of agricultural products. St. Petersburg, International Conference of the Institute of Cold. 2013. 352-353.
4. PP
production
http://www.center- pack.ru/articles/polipropilen-i-oblast-ego-primeneniq 5. http://agrosetka.ya.ru.
6. http://agrobiznes.ru/agro/agroprod. 